\title{
LIFE INSURANCE AS A SOCIAL SERVICE AND AS A MATHEMATICAL PROBLEM*
}

BY ROBERT HENDERSON

The prophet Ezekiel in describing the wonderful vision which appeared to him by the river Chebar uses an expression which has become proverbial. He describes four living creatures and speaks of each as accompanied by a wheel. Regarding these wheels he says "their appearance and their work was, as it were, a wheel within a wheel". I hope that if you get from this talk of mine the impression that the business of life insurance is like the vision of Ezekiel "wheels within wheels", I shall be able to make clear to you that it is like that vision also in the further respect that as Ezekiel also says "the spirit of life was in the wheels". If there is, or ever was, a business which is the embodiment and outgrowth of a vital principle it is that of life insurance.

That life insurance performs a very important social service is shown by the remarkable vitality through the ages of institutions attempting in a small way to furnish benefits which were essentially life insurance and by its remarkable growth in modern times after the correct scientific basis had been discovered.

The recorded history of the world has largely to do with states, their rulers and their wars, and it is only by the chance survival of documents that we learn of those social forces and institutions which did not come to the attention of the rulers as subjects of regulation. It is probably for this reason that we first hear of insurance benefits in connection with voluntary associations or collegia because, while voluntary associations appear to have been comparatively free in the days of the Roman republic they were

* Delivered before the Society and their guests, as the Josiah Willard Gibbs Lecture, at Washington D. C., December 30, 1924. 
the subjects of very rigid regulation under the emperors and only those whose objects met with the approval of those in authority were permitted to exist legally.

The particular associations which come to our attention as embodying life insurance benefits appear to have been in the first place religious societies devoted to the worship of particular deities. In view of the religious element involved in funeral rites a provision for the performance of those rites at the death of members of the society was, therefore, a natural development and might be considered as merely incidental were it not for the fact that this feature appears to have had such vitality that associations came into existence which, so far as we know, had no other object. Some of these societies had their own burial place or columbarium, according to the mode adopted for disposing of the body, while others seem to have merely paid a cash sum at death for the purpose of defraying the necessary expenses.

The membership of these societies of which we are speaking was composed of slaves and other very poor people, so that the benefits were extremely small. For example, in one case the entrance fee was equivalent to three dollars and a half and an amphora of good wine and the monthly contribution to about four and one-half cents. The funeral benefit paid by this society was equivalent to about ten and one-half dollars.

These societies, called Collegia Tenuiorum on account of the grade of society from which their membership was drawn and also called Collegia Funeraticia or burial societies, where, as was usually the case, the death benefit was the predominant feature, were not the only societies of ancient days which involved the life insurance feature. There appear to have also been societies among the soldiers with similar benefits on a somewhat larger scale but associated with other benefits more expensive. For example, one such society of which there is record paid about seventy dollars in case of death on service. The same 
amount was also paid in case of promotion to a higher rank, transfer to another legion or retirement. The consideration for all of this seems to have been an admission fee of one hundred and five dollars, possibly payable in instalments.

From the nature of the case these associations were not organized on a scientific basis nor carried on in a systematic manner so that they sometimes failed just as institutions similarly organized on a larger scale have failed in modern times.

The principle of cooperation and mutual support, in the face of contingencies that are unforeseen or overpowering, which underlies all forms of insurance is very strongly illustrated also by the gilds which were so important a feature of the middle ages commencing with the Frith Gilds of early times, which had many analogies to the vigilance committees of our frontier days, being voluntary associations of neighbors for that mutual protection and support which the government of the day could not be depended upon to give, and developing through the merchant gilds, the craft gilds and the social and religious gilds. Even in the case of the latter, however, the relief given in case of death was not for death as such but was conditioned on resulting destitution and did not, therefore, exhibit the principle of life insurance as distinctly as did the Roman burial societies. They represented, in fact, insurance against destitution of self or family instead of insurance against any of the contingencies which might cause financial loss.

While, however, the Roman Collegia and the mediaeval gilds illustratc the fundamental social value of insurance and especially of life insurance, it is to a different organization that modern life insurance companies are directly linked. The loss sustained by the merchant and shipowner, the two being frequently if not usually in early days one person, must always have been a staggering one. It is only natural, therefore, that marine insurance should have been the first 
form of insurance to be practiced on an extensive scale. In the early days it appears to have been entirely, as it still si largely, undertaken by individuals not organized into a partnership or company but each separately assuming the amount of risk set opposite their signatures subscribed to the policy of insurance. Hence the origin of the name "underwriters" for those assuming insurance risks.

Out of marine insurance there grew a practice of also insuring the life of the merchant or of the master of the ship for the voyage. These early life insurance policies were probably looked upon as merely marine insurance policies, the perils of the sea being those principally in mind in connection with them and they were underwritten by individuals in the same way as the regular marine policies.

The earliest life insurance policy of which we have a record was dated June 18th, 1583 . We haye a record of this policy because it was the subject of a trial in the English courts. It was made at the Office of Insurance "within the Royal Exchange" in London and insured the life of one William Gybbons in favor of Richard Martin for a period of twelve months from its date at a premium rate of eight percent. The insured died May 29, 1584 and claim was duly made for the amount insured but the underwriters denied liability on the ground that the insured had survived for more than twelve lunar months of twenty-eight days each. The Commissioners of the City of London, the Clerk of the Office of Assurance and finally the Judges of the Court of Admiralty all ruled against the underwriters and they were required to pay.

In passing it may be as well to note that the wording of this policy shows that life insurance transacted in this manner had for some time been a recognized practice. It says (modernizing some of the language) "It is to be understood that this present writing is and shall be of as much force, strength and effect as the best and most surest policy or writing of assurance which hath been ever heretofore 
used to be made upon the life of any person in Lombard Street, or now within the Royal Exchange in London" and further on refers to "the use and custom of the said street or Royal Exchange".

The next decisive step towards the modern system of life insurance was taken when, in 1699, there was founded in London the first mutual contribution life office. It was called "The Society of Assurance for Widows and Orphans". The plan was to have a society of 2000 members each of whom paid 5 shillings toward each death claim and an additional 5 shillings once for all on admission and one shilling quarterly. The amount paid in case of death was the 5 shillings from each member, making $\$ 500$ in all if the number of 2000 were complete, less a deduction of 3 percent for expenses. The provision for running expenses was thus the admission fees, the quarterly dues of one shilling from each member and 3 percent of the claim contributions. Immediately upon the payment of a death claim the 5 shilling contribution for the next claim was collected and it was also collected from each new member in addition to the admission fee.

Two other similar institutions were established in 1700 and 1704 respectively but all three and many others which had been floated in the meantime were swept out of existence when the South Sea Bubble burst in 1720 .

An institution was, however, established on slightly different lines in 1706 which was able to survive the disastrous year 1720. It was called the Amicable Society for a Perpetual Assurance. The contributions of the members were fixed at $£ 6.4$ s per annum and an admission fee of 10 s. The number of members was fixed at 2000 which number appears to have been attained in the second year. The amount paid as a death claim depended upon the number of deaths in the calendar year. The provision was that in the first year of the Society one sixth of the total contributions was to be divided among the death claims of the year, in the second year, on the assumption of a 


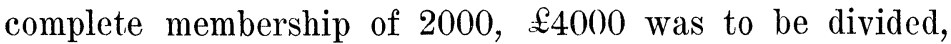
in the third year $\$ 6000$, in the fourth year $\$ 8000$ and thereafter $\$ 10,000$ each year. As the full contribution from the complete roll of members, after deducting 4 shillings per annum from each which went to the registrar, amounted to $£ 12,000$ this left a liberal margin for accumulation of surplus so that even though it suffered some financial reverses in its early years it was able to survive. In 1807 its business was placed on a more scientific basis and in 1866 after 160 years of existence it was amalgamated with another company which is still in existence. In order to complete this historical review of prescientific life insurance it may be added that in 1721 two corporations, the London Assurance Corporation and the Royal Exchange Assurance Corporation, which had been already authorized to transact marine insurance, received the additional power to accept life insurance risks. They transacted the business on the old lines which had been followed by individual underwriters. The standard premium seems to have been 5 percent for all accepted ages.

We have thus traced the history of life insurance up to the time when the science of life contingencies as an application of mathematics was developed. It is an interesting fact, however, that although, up to the present time, life insurance has been the most important business to which that science has been applied it was not in connection with life insurance that it was first developed but rather in connection with life annuities. It must be remembered that although life annuities are affected by the same contingencies of life or death as is life insurance and while at the present time the great bulk of the business of granting life annuities is carried on by life insurance companies they serve a fundamentally different purpose and had a radically different origin.

With respect to life annuities our search for origins leads us back, as in the case of life insurance, to ancient Roman days but instead of associations of slaves we have 
in this case the testamentary dispositions of the wealthy who directed that certain legatees should receive out of their estate a fixed income for life. Out of this practice a problem arose when a law was enacted that at least one quarter of any estate should be distributed among the legal heirs. For the purpose of determining if this law was complied with it was necessary to have some rule for finding the commuted value of these obligations to pay an income for life and a schedule of values graded according to quinquennial groups of ages of the life tenant was actually drawn up and used for that purpose. We have no record, however, of the basis upon which the figures in that table were arrived at nor of any investigations which would furnish appropriate data, so that as far as we can judge it was purely empirical or hypothetical.

There are probably instances in all subsequent ages of such life interests or annuities arising out of wills but it was from a different source that the great impetus to the business of life annuities come.

In early days no distinction was made between excessive and moderate rates of interest for loans. Possibly there were no instances of a moderate rate but in any event all interest or usury as it was called was condemned. This condemnation was at first a purely religious one but at various times laws were enacted by the civil authorities in various countries prohibiting usury. In some cases this prohibition was general but in others it applied only to the Christian subjects of the state so that non-Christians and aliens were permitted to practice it. The economic tendency which these church edicts and civil laws were endeavoring to combat was, however, so strong that even the clergy seem to have in many cases engaged in the practice. Capital, however, in the hands of men of ordinary prudence prefers a legal investment if it can be found. A legal way of satisfying economic needs was accordingly sought and found in the purchase and sale of rent charges and life interests. These were at first always charged 
against specific parcels of real estate the owner of which, desiring to raise an immediate sum of money for some purpose. would agree to a definite annual charge against the income from the property either in perpetuity or for the lifetime of one or more nominees. Later these annuities were sometimes issued on the personal credit of the granter and in such cases were almost necessarily either for life or for a fixed term of .years.

The sale of annuities was not confined to individual property owners. As early as the eighth century monasteries and other religious bodies sold life leases of land or rents for life. This means of raising money became popular with public bodies and from about the end of the thirteenth century it was largely monopolized by them, both town authorities and governments of states taking part in it. Many towns, in fact, forbade the sale of annuities by private persons and while in this step they may have been actuated by the motive of removing competition there were probably also actual complaints of abuses in the private sale.

Annuities were issued on two or more lives payable as long as any of the nominees survived. The income might be payable to the purchaser or his heirs the lives nominated not being financially interest in the contract or it might be payable to the nominees in a definite order of succession or in the third place might be equally divided among. the survivors or their respective nominators. This latter plan with a large number of nominees develops into the form of annuity plan associated with the name of Tonti and therefore called tontines.

It is evident that if such an annuity is established on say ten thousand lives of sufficient amount to give each ten dollars a .year at the start it will give very large incomes to each surviver near the end. This form of contract has for the individual purchaser a very considerable gambling element and for the seller is very nearly equivalent to a perpetuity. 
This form of contract was quite popular in the seventeenth century in Europe and is of interest to us from the fact that a feature developed in connection with it which, I believe, helped to prepare the way for the scientific study of life contingencies. Taking a glance forward to the deferred dividend or tontine dividend system of profit distribution formerly so popular in this country and comparing it with this tontine annuity scheme it appears that with anything of the tontine nature estimates of results are almost inevitably associated. The promoters of tontine annuity schemes sometimes put out such estimates showing out of a given number of annuity purchasers the estimated number surviving after various intervals and the consequent income received by each.

Unfortunately, however, for historical completeness there is, so far as I know, no record of any of them explaining the basis of the estimates. They did, however, undoubtedly accustom people to the idea of the possibility of estimating how many out of a given group of people now formed would remain alive at any given date in the future and how many would die in each year.

Having thus outlined the steps by which the force of circumstances prepared the problem of life contingencies for the attention of mathematicians let us now turn our attention briefly to the other side of the screen and observe how mathematical science was being prepared to attack the problem. This leads us to a consideration of the foundation of the theory of probabilities and although any remarks of mine on this subject before this audience may possibly be likened to "carrying coals to Newcastle", I shall, for the sake of completeness, ask you to bear with me for a few minutes.

Although there are slight hints of the subject in the writings of Cardan, Kepler and Galileo the definite origin of the science is usually, and with justice, attributed to Pascal. With his name is associated that of Fermat who was consulted by Pascal and who worked out an independent 
solution of the problem under discussion. It is interesting to note that at the date, namely 1654 , when they discussed this problem and so laid the foundations of the theory, Pascal and Fermat were the most distinguished mathematicians of Europe, Wallis in England being practically their only rival. Descartes had died in 1650, Newton was only twelve years old, and Leibnitz eight. Another interesting fact is that both of these founders of the science might be classed as amateur mathematicians, by which I mean that mathematics was to each of them an avocation or hobby and not a source of income. Pascal had just the year before been called from his religious retreat at Port Royal to administer his father's estate and was at the time occupied with that business. He returned to the retreat in November of 1654 . Fermat was and had been for twenty-three years councillor for the local parliament at Toulouse. He was at the time about fifty-three years of age and Pascal was thirty-one.

A third interesting fact is that the problem which brought the subject to Pascal's attention was itself of comparatively little importance and arose out of a game of chance. This may perhaps be considered natural because the subject matter of the science is chance and games of chance, at that time at least, received more attention than any other chance events.

The problem was proposed to Pascal by the Chevalier de Meré, who seems to have been addicted to games of chance, and was in substance as follows: Two players want each a given number of points in order to win. If they separate without playing out the game, how should the stakes be divided between them? It will be seen that this is equivalent to determining their respective chances of winning the game. This problem was solved on the assumption that the two players had equal chances of winning any particular point and that this was true regardless of who may have won any other point.

The methods followed by the two mathematicians in attacking the problem differed but their fundamental 
assumptions were the same and the results consequently the same.

Pascal applied the method to some allied problems and intended to write a treatise on the subject but the accident which was the occasion of his return to the Port Royal retreat occurred shortly after and he does not appear to have ever carried out his intention. He died in 1662 at the age of 39. Todhunter in his History of the Theory of Probability says

"It might have been anticipated that a subject interesting in itself and discussed by the two most distinguished mathematicians of the time would have attracted rapid and general attention; but such does not appear to have been the case. The two great men themselves seem to have been indifferent to any extensive publication of their investigations; it was sufficient for each to gain the approbation of the other. Pascal finally withdrew from science and the world; Fermat devoted to mathematics only the leisure of a laborious life, and died in 1665".

The work of systematic presentation was taken up by Christian Huygens who wrote in 1657 a small treatise on the theory of probabilities founded on the correspondence of Pascal and Fermat. It was first published in Latin at the end of a collection of mathematical exercises by Frans van Schooten. This little treatise is notable because for a period of more than fifty years it formed the best account of the subject and it was during this fifty year period that the foundation of actuarial science was laid down. It is interesting to note that van Schooten's collection was one of the books read by Newton as an undergraduate at Cambridge. It would seem probable that Halley was also familiar with it or at least with the treatise by Huygens in view of the fact that a translation of it was included in an anonymous essay edited by Motte and printed in England in 1692. It was in this treatise of Huygens that the term expectation in the sense in which it is used in probabilities was first introduced. 
Although, contrary to the usual opinion, the expectation of life is not a fundamental element of actuarial computations and is in fact merely a convenient basis of general comparison between different mortality tables the idea of expectation as developed in the theory of probability is fundamental. Its explicit introduction in this treatise is, therefore, worthy of note. The idea itself was, of course, implicit in the original problem proposed to Pascal. The quantities sought in that problem were the respective expectations of the players if play had been continued.

The calculus of probabilities, young and neglected as it was, had now reached a stage where it was ready for application to the problems of life contingencies and although the birth of actuarial science is usually referred to the first known calculations involving a combination of the theories of compound interest and of probabilities it may be well in passing to mention a development which immediately preceded that event. I refer to the publication in 1661 by Captain John Graunt, a London merchant, of a book entitled Natural and Political Observations on the Bills of Mortality. In this book, besides giving valuable statistics of deaths analyzed by cause and by age, an effort was made to draw conclusions regarding population and rates of mortality, including a table showing how many in each hundred die within the first six years of life and how many in each decade thereafter. This table was used twentyone years later in connection with a tontine scheme as furnishing an outline mortality table. Considerations which must be taken into account if a mortality table anywhere near correct is to be obtained were apparently ignored and the table has no claim to accuracy as a representation of the rates of mortality. It will be interesting to compare the percentages of those entering each age interval who die in that interval according to this table with those according to the Carlisle Table which was the first based upon a comparison of deaths analyzed by age with the corresponding population. They are as follows: 


$\begin{array}{ccc}\begin{array}{c}\text { Age } \\ \text { Interval }\end{array} & \begin{array}{c}\text { Percentage of } \\ \text { Graunt }\end{array} & \begin{array}{c}\text { Death } \\ \text { Carlisle }\end{array} \\ 0-6 & 36.0 & 33.2 \\ 6-16 & 37.5 & 6.2 \\ 16-26 & 37.5 & 6.8 \\ 26-36 & 36.0 & 9.1 \\ 36-46 & 37.5 & 12.2 \\ 46-56 & 40.0 & 14.1 \\ 56-66 & 50.0 & 27.7 \\ 66-76 & 66.7 & 47.7 \\ 76-86 & 100.0 & 75.8\end{array}$

It will be noted that in Graunt's table these percentages are substantially the same for the five decennial intervals from age six to age fifty-six and correspond with an annual rate of about forty-six per thousand, a rate not reached in the Carlisle table until age sixty-eight.

While this book is clearly entitled to first place in the history of vital statistics it is difficult to define its relation to our subject because we cannot trace any definite connection between it and the preceding work of Pascal, Fermat and Huygens in the calculus of probabilities on the one hand nor between it and the subsequent actuarial developments on the other.

We now come to the definite starting point of actuarial science. It is a curious fact, however, that in one sense this starting point is not definite because the first piece of actuarial work on record has apparently no connection with the subsequent development of the science, which, in fact, followed continuously from an independent origin. This was partly due to special circumstances but the whole incident clearly demonstrates the value of scientific societies for the preservation and dissemination of the results of original research.

The importance of these incidents in connection with our subject will perhaps excuse some reference to the individuals concerned, as that will give a clearer idea of the circumstances. The author of the first actuarial report 
was John deWitt, Grand Pensionary of Holland from 1653 to 1672 . He was born at Dort in 1625, his father being a prominent leader of the party which was opposed to the extension of the executive power then vested in the Prince of Orange as elective stadtholder. The position of stadtholder of the United Provinces was in practice hereditary in the house of Orange but a formal election was necessary at each vacancy and when in 1650 the stadtholder, William II, died, leaving only a posthumous son born one week after his death, the post of stadtholder was left in abeyance and the chief executive authority devolved on the Grand Pensionary of the Province of Holland. Young John deWitt was elected to this position in 1653 at the age of twenty-eight and being re-elected at five year intervals he continued as the head of the government until 1672. Then when the young prince, William III of Orange, afterwards King William III of England, had attained his majority and the country was engaged in war against France and England a violent reaction not only drove John deWitt from power and installed William III as stadtholder but resulted in the murder of JohndeWitt and his brother Cornelius by a mob on August 20, 1672.

Before his election as Grand Pensionary he had already in 1650 , displayed his interest in mathematics by writing a treatise on curved lines and it was natural, therefore, that he should take a personal interest in the questions of a mathematical nature which came up during his administration.

Reference has already been made to the custom of municipalities and other governments raising money by the sale of life annuities, the purchaser being allowed to nominate the person on whose life the annuity was to depend. The ordinary terms appear to have been that a life annuity was considered as worth one half of the value of a perpetuity of the same annual amount so that, for example, on a four percent basis, a perpetuity being worth 
twenty-five years' purchase, a life annuity would be worth twelve and a half years' purchase. In the case, however, of the annuities sold by the government of Holland this seems in deWitt's time to have already been modified so as to require fourteen years' purchase instead of twelve and a half.

The object of deWitt's report was to show that a life annuity at fourteen years' purchase yielded a better return to the purchaser than a redeemable annuity or perpetuity at twenty-five years' purchase. This he does by calculating the value at age three, on a four percent interest basis, of a life annuity of 20,000,000 stuyers per annum payable half yearly. He assumes that the same number die in each half year for fifty years from age three to age fifty-three, then two-thirds as many each half year for the next ten years, one half as many for the next ten years and one third as many for seven years and that all are dead at age eighty. His method of calculation is to multiply together the number assumed to die in each half year and the present value of the annuity they will each have drawn and to divide the sum of these products by the total number. It will be seen that this is a direct calculation on the principles of the theory of probability of the expectation of the purchaser.

The report itself does not attempt to justify the assumptions made regarding the distribution of deaths but in subsequent correspondence with John Hudde, Burgomaster of Amsterdam, and also of some note as a mathematician, he indicates that they were based in some way on observations. He states that from further observations he believes that the uniform decrements should extend up to age seventy-five.

The value which he had arrived at for a life annuity at age three was just over sixteen years' purchase and in a supplementary report he indicates a practical check which he had applied. He says that he had extracted from the records the data regarding several thousand purchasers of annuities and had calculated the average value of the 
annuities drawn in each of considerably more than one hundred classes of about one hundred lives each and that in no case had he found the average value less than sixteen years' purchase but they were frequently much higher, even up to eighteen years' purchase. Only a few copies of this report were printed and, possibly due in part to the troubles of the following year, when deWitt was driven from power, all trace of the report was lost although the fact was known that it had been made and it was not recovered until the middle of the last century, when, through the researches of Frederick Hendriks, a copy was found in the archives of the Netherlands.

The next to venture in this field, while not so prominent politically as de Witt, was much more prominent scientifically. I refer to the famous astronomer Edmund Halley. It is unnecessary to recite to this audience the fact that he was the first to calculate the periodic time of a comet nor the great service to mathematical and physical science that he rendered by inducing Newton to write his Principia. The whole cost of its publication was borne by Halley who also corrected the proofs.

If the results which flowed from Halley's work illustrated as we have already pointed out the value of scientific societies for the preservation and publication of original work his actually undertaking it illustrated their value in actually stimulating such work. He was at the time actively interested in the work of the Royal Society and in order to insure the continuation of the publication of its TransACTIONS he undertook at a meeting of the council in December, 1692, to furnish five sheets in twenty himself. It was probably under the spur of this promise that he took up the analysis of the data regarding births and deaths in the city of Breslau which had just recently been contributed to the Society and the result was a paper entitled An estimate of the degree of mortality of mankind, drawn from curious tables of the births and funerals at the city of Breslau; with an attempt to ascertain the price of 
annuities upon lives which was presented early in 1693 . It is notable as containing the first known example of a complete mortality table. This table was constructed from the deaths during the five years 1687 to 1691 inclusive on the assumption that the population was stationary and that consequently the number attaining any age would equal the number of deaths above that age. It was not quite in the usual modern form because the number shown opposite each age was not the number attaining that precise age but the number living at any given moment in that year of age, for example, opposite age 25 we find the population at age 25 next birthday. These figures can of course be used in the calculation of annuity values just like the usual number living $\left(l_{x}\right)$ column of a mortality table provided we remember that the value so arrived at corresponds to age next birthday and not to exact age.

Among the uses for this table suggested by the author are the determination of the premiums for what we now call one year term insurance and the valuation of annuities on one life, on two lives and on three lives. His formula for the value of a life annuity is the one still used in explaining the elementary theory of the subject and represents the sum for positive integral values of $n$ of the products of the present value of a unit due $n$ years hence and the probability that the life or lives on whose survival the payment was conditioned would survive the $n$ years. For an annuity on one life this was mathematically equivalent to the formula used by de Witt but was simpler in practical operation and more easily applied to two or more lives. In a subsequent communication he points out the great advantage of using logarithms for these calculations. The more practical methods proposed by Halley and this later suggestion regarding logarithms shows the effect of his experience with arithmetical calculations in connection with his work in astronomy.

The work of these two independent pioneers brings out the fact that the work of actuarial science like that of 
[May-June,

every other branch of applied mathematics falls into two main divisions. The first is the ascertainment of those facts of nature which can be used as premises for the mathematical calculations, in this case primarily the facts regarding human mortality, although the rate of interest appropriate to the particular problem in hand and the rate of expense necessary to be provided for are also factors. The second is the development of the mathematical processes best suited to the problems arising and in this division economy of labor is second in importance only to substantial accuracy of result. It may be of interest to outline the main problems which come up for consideration in each of these divisions, merely prefacing the whole with the remark that there is a very considerable mathematical element in the first division as well as in the second.

It might appear that the straightforward way of constructing a mortality table from actual experience was to take note of a large number of babies born about the same time and have them all observed until the last one died, noting the number dying in each year of age. The mere statement of the process, however, shows that it is impracticable. Some other process is therefore necessary and it was perhaps fortunate for the business of life insurance that the methods first followed erred in the direction of too high rates of mortality so that the premiums charged were higher than proved ultimately necessary. Graunt's figures were apparently a simple analysis by age of the deaths reported in London during a few years. The basis of deWitt's calculations was stated as a pure hypothesis without any attempt at justification in detail. Halley apparently recognized the disturbing effect of migrations and of a rapidly changing population. Owing, however, to the fact that the recorded births in Breslau only slightly exceeded the recorded deaths he assumed that the population might be considered stationary. He, therefore, graduated by inspection the average number dying per annum at the various ages and assumed that 
this gave the decrements of the table, the number living being given by summing from the oldest age downwards. The next important landmark is from one point of view a backward step, appearing to substitute hypothesis for observation, but from another point of view it might be considered as the first attempt to graduate a mortality table by a mathematical law. I refer to deMoivre's hypothesis that the number dying was the same at all ages with eighty-six as the limiting age. I refer to it as a graduation because the smooth series of the hypothesis agreed in a general way, except in infancy and extreme old age, with Halley's and later tables constructed on the same principle that were current at the time he propounded it. This brings out the point that the first division of subject consists of two parts, the ascertaining of the crude facts observed and the adjustment of the results. In fact; Halley in constructing his table had not used the schedule of deaths exactly as reported but had substituted a smoother series.

With regard to the ascertaining of the crude facts the greatest advance was made with the construction of the Carlisle table by Milne because he was able to put into effect the principle that in the construction of a mortality table the fundamental functions are the rates of mortality at the successive ages and not the deaths at the various ages. These rates of mortality he was able to calculate because he had as data not only the deaths in the parishes of St. Mary and St. Cuthbert, Carlisle, for the nine years 1779 to 1787 classified by groups of ages but also the population January 1st, 1780, classified in substantially the same way and an estimate at least of the increase in population up to December 31st, 1787. I speak of it as an estimate at least becanse the figures used indicate an increase of exactly 1000 . It is interesting to compare these various tables and hypotheses including the Northampton table constructed by Dr. Price from the deaths in the parish of All Saints, Northampton, during the forty-six 
years from 1735 to 1780 inclusive. I have chosen for the purpose of comparison the probability of a child aged six years dying within thirty years and the similar probability at age forty-six. The comparison is as follows:

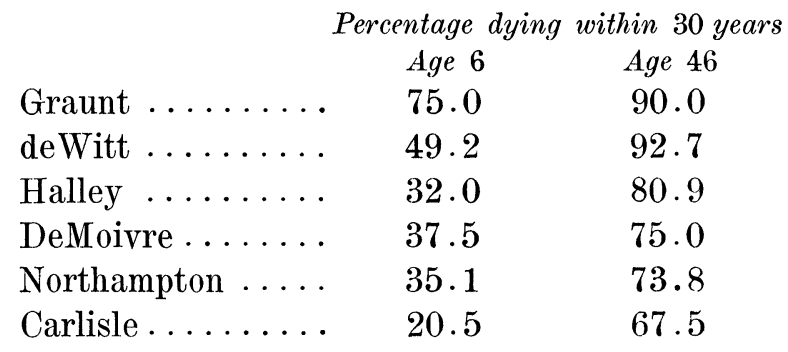

The marked excess of the early estimates of mortality at young ages is very noticeable.

The problems involved in the tabulation of the unadjusted rates of mortality derived from returns relating to the general population differ in many particulars from those arising in connection with insurance experience. On the former the returns since the day of systematic periodic censuses and fairly accurate death registration furnish ample data and the special problems arose at first from the fact that the age classification was only made for groups of ages and the principles of finite differences had to be applied to obtain the rates for individual ages. In later years when returns were made for individual ages we are confronted by the fact that people have a bias in favor of round figures of various kinds in stating their ages so that a careful regrouping is necessary to minimize the error from this source. Also experience indicates a deficiency in the enumerated population in the first two years of age and the question of an approximate correction of the deficiency is an interesting one. In insurance experience the ages are more accurately known and the primary problem is the practical treatment of those withdrawing from the field of observation otherwise than by death. As the requirements of the business, however, 
progress we find that a simple classification by attained age is not sufficient. We must investigate special classes of risk on account of sex, residence, occupation, physical impairment or other special features and in doing so must take account of the fact that the rate of mortality depends also on the time elapsed since the life was accepted for insurance. In other words for insurance purposes a man is not simply a man of a given age but we know that other ascertainable features affect the probabilities of death.

The graduation or smoothing of the crude rates of mortality is justified by the fact that according to the theory of probability the actually observed ratios of death are not likely to agree exactly with the true probability and indeed cannot unless the product of the probability and the number at risk happens to be an integer. Also a fluctuation in one direction at a given age is as likely as not to be followed by a fluctuation of opposite sign at the next age. An actually observed irregular series is therefore not inconsistent with the natural assumption that the series of true probabilities is a smooth one. Various methods have been used to graduate mortality tables. Halley's table and the Northampton table were graduated roughly by simple inspection. Milne used a graphic method to distribute the population and deaths into individual years in such a way as to preserve the totals of each group of ages unchanged. We have already mentioned deMoivre's hypothesis as possibly entitled to be considered a sort of graduation by mathematical law but the law most extensively applied to the graduation of mortality tables was Makeham's modification of Gompertz' law. Gompertz originally suggested that the force of mortality or instantaneous death rate increased in geometrical progression with the age. It was, however, found impossible to use a single rate of progression throughout even adult life so that it was necessary to break the table into two parts using one rate for one part and another for the other. To overcome this difficulty Makeham proposed breaking 
[May-June,

the force of mortality into two parts, one of which remained constant and the other increased in geometrical progression. With this modification it was found possible to reproduce with a fair degree of accuracy the mortality indicated by a number of different tables from an age in the twenties to the limit of life. This law possesses advantages in connection with joint life calculations so that it is desirable to use it if possible but recent experiences have been rather intractable. In the case of the experience on American insured lives recently published by the Actuarial Society it was necessary to introduce an additional term into the expression for the force of mortality in order to fit the table from age $30 \mathrm{up}$. This term was negative in simple proportion to the age.

Other formulas have been used, some of them very elaborate, but no particular one has been used generally and none of them possess the practical advantage of Makeham's.

A third general method of graduation is based on the principle of moving average. As first applied it consisted in substituting for each term of the series the average of five consecutive terms of which it was the central and then repeating the process a second and third time. This, however, would introduce an error into a regular second difference series so a correction is introduced to eliminate this error so that a regular third difference series would be reproduced. Many variations have been suggested and the investigation of the smoothing power and residual error of the various formulas is an interesting problem. A fourth plan which has been used is to apply the principles of finite differences to determine adjusted values for the exposed and deaths at quinquennial ages and then having calculated from these the rates of mortality at those ages to fill in the remainder by interpolation.

A new method of graduation has recently been put forward by E. T. Whittaker of Edinburgh which consists in determining a graduated series of values such that the 
sum of the squares of the third differences of those values plus the sum of the squares of the differences between the corresponding graduated and ungraduated terms multiplied by a selected constant shall be a minimum. This requirement gives a linear difference equation of the sixth order with end conditions sufficient to determine uniquely a particular solution which is the graduated series required. It is evident that the graduating power depends on the constant selected. The smaller the value of the constant the smoother the resulting series and the greater the sum of the squares of the departures of the graduated from the ungraduated values. For all values of the constant the algebraic sum of the departures and of those departures multiplied by the respective ages or by the squares of the ages will vanish.

Taking up now the other division of our science, namely, the development of the mathematical processes suited to its problems, it will be recalled that the methods of Halley brought out the element so frequent in actuarial calculations, of the determination of the value of an expectation. Where the benefit as in the case of a life annuity payable annually consists of payments to be made on the anniversaries of the date of calculation provided specified contingent events have happened this is theoretically simple. The only difficulties arise from the complicated probabilities sometimes met with. The case of life insurance is ordinarily brought under this heading by assuming that the sum insured is payable at the end of the year in which death occurs. As the possible future life time extends over a considerable number of years the preparation of a table of values if calculated independently is rather laborious. Delloivre accordingly showed how the value of a life annuity at any given age may be derived by a short calculation from that at the next older age and a similar principle may be applied to other values. His formula is still of theoretical value and of occasional practical use but for general purposes has been superseded by the device of commutation columns, the fundamental idea of which is the discounting 
[May-June,

back not to the present time but to the date of birth of the total payments called for if a contract of the kind being valued were in force on every life represented by the number living according to the mortality table used. The functions, therefore, which enter into valuation at one age enter largely into the value at another age and certain functions are found of very wide availability thus yielding a great economy of labor.

The principles of finite differences or of the infinitesimal calculus come into play in cases of two kinds. In the first case periodical or other payments may be payable otherwise than annually on the anniversary and it may be desired to derive formulas as accurate as possible for the present values not necessarily for actual use but in order to know the limits of error in the simpler formulas actually used. For such cases formulas have been derived for the correction to pass from the annual case to the fractional. Again the probabilities involved in a particular problem may be so complicated that their calculation for every year of possible future duration of the contract would be too laborious. In such cases they are calculated only at intervals and the principles of finite differences applied to obtain approximate values on the assumption that the probabilities vary regularly in the intervals.

In this connection it is interesting to note that the development of the theory of osculatory interpolation has come almost entirely from the needs of life insurance calculations. The curves used for interpolating in the successive intervals are so adjusted as to pass smoothly into one another without using too high an order of differences. Such a method was more necessary in life insurance than in astronomical work because the basic values which must be used upon which to interpolate are not quite as regular as the calculated values occurring in astronomy.

I have thus outlined briefly and, let us hope, not too tiresomely the nature of the mathematical processes required for actuarial calculations. Let us review a few of the 
results that have followed the development of the business.

Life insurance still serves in increasing measure the special purposes which called it into existence and as it was the demand for what we would now call business insurance which had sufficient financial importance to call for the establishment of life insurance corporations so it is appropriate that to-day the same demand should call for the largest policies and furnish the most interesting news items. Large amounts of insurance are called for by wealthy people to cover inheritance taxes or to provide ready money to meet the obligations likely to mature at their death. Partnerships ask for it to provide ready money to settle with the estate of a dead partner without sacrificing the business. Businesses which are largely built about the skill, technical knowledge or executive capacity of some individual demand insurance to compensate in a measure for their loss. The purpose, however, of life insurance which is of the greatest social importance is to continue in part and for a time at least to the dependents of the insured the income and support which would otherwise cease at death. To this has recently been added the furnishing of a similar support to the insured himself and his family should he suffer from total and permanent disablement which is, financially at least, worse than death. It has also developed the service which it offers freely to the beneficiaries of life insurance policies of holding the proceeds, investing them for the beneficiaries and paying principal and interest in such convenient manner as may have been arranged thus relieving a beneficiary, probably inexpert and certainly unprepared, from the trouble and risk of seeking investments.

An additional important social service performed by life insurance arises from the necessity of finding investment for the reserve funds which the companies must accumulate and upon which they must earn interest. I might dwell at length on the way in which life insurance funds have aided in the development of our farms and railways and 
in the building of our cities but this feature of its service has been put so much better than I could do it, by the late Mr. Peter McArthur, that I conclude by quoting some extracts from a pamphlet which he published a few years ago. He says:-

"In this time of discontent it should be made clear that no matter what accusations are brought against wealth, insurance money is unselfish money. This has not been clear in the past. Possibly it has not always been true. But insurance funds have now reached such proportions that their real nature is becoming evident. The inherent laws that govern insurance money are being released and their power is becoming apparent. In spite of what any man or group of men may do these great accumulations of the savings of the people are bound by their very nature to be on the side of the people and to work for them. As they go on increasing they will do more and more to safeguard the rights of humanity. In short, I have no hesitation in saying that insurance is now the most steadying force in our civilization.

"It is estimated that in the United States the established fortunes that are devoted to investment rather than to active enterprise amount to something over $\$ 15,000,000,000$. The insurance funds already equal fully one-half of this amount and at their present ratio of increase will probably exceed it in a few years. In Canada the conditions are much the same. While no man can predict what will be the entire result of this competition between the great fortunes and the insurance companics for possession of the most desirable securities, the power of individual wealth will certainly be curtailed and the safety of the people will be increased. This is the first time in history that anything of this kind has occurred. In the gamble of life the percentage was always in favor of those who had reserves of wealth. Now, however, life insurance is putting the percentage in favor of the ordinary people."

Equitable life Assurance Society 